Paul Law

\title{
Some conceptual and empirical issues in linguistic theory: An illustration with pronominal clitics
}

\section{Introduction*}

I would like to discuss a few general conceptual issues in linguistic theory, and show how they bear on some empirical facts about pronominal clitics. In particular, I would like to show that the conception of linguistic theory, justified on independent grounds, limits the class of issues and possible explanations for grammatical properties of specific linguistic expressions. I argue that this is not simply a consequence of a specific conception of grammar, conceived of as a system of principles and rules governing language, but has non-trivial empirical ramifications. Pronominal clitics are a good case study, since their grammatical properties bear on a wide range of facts falling under the purview of principles of phonology, morphology, syntax and semantics.

I will first briefly discuss the constraints on scientific theory in general, encompassing theory of language or any other empirical science (section 2). These will set some conceptual conditions on linguistic analysis, e.g. what issues it should consider, and what explanations are conceptually more plausible than others. I argue that they are not the conceptual bounds that we must accept a priori, but have empirical bearing. Thus, to the extent that we can determine whether the empirical predictions of linguistic theory are correct, the conceptual conditions to which linguistic theory are subject are empirically warranted. I then consider some specific properties of pronominal clitics, and argue that given the general constraints on linguistic theory there is no need for an independent category of pronominal clitics (section 3). Moreover, I show how the constraints on linguistic theory shed light on the grammatical principles underlying some of the well-studied properties of pronominal clitics (section 4).

The goal of the paper is to show the relation between the conceptual framework for linguistic theory and its bearing on empirical facts. That is, what empirical facts we should expect to see or not to see, if linguistic theory is correct. I will therefore not review the extensive literature on pronominal clitics or go into the very many details of their analysis. As we will see, certain aspects of clitics are obscure, and would probably remain so for some time to come. The major difficulty is that there are apparently very few other elements sharing the same properties as pronominal clitics. And given the general conceptual constraints on linguistic theory, it is often not easy to justify,

* I would like to dedicate this article to Ewald Lang. It certainly is a disproportionately small token of my gratitude to his support over the years. I would like to thank Luis Lopez-Carretero for his help with Spanish, Livio Gaeta and Gloria Cocchi for their help with Italian, and Alex Grosu for his help with Rumanian. 
crucially independently, particular assumptions for the analysis of pronominal clitics, there being too few independent facts that can be brought to bear. Despite this difficulty, and given the conceptual bounds on linguistic analysis, we can see the adequacy of a particular account, and the possible alternatives.

\section{Constraints on linguistic theory}

Like any scientific enterprise, linguistic theory is subject to the conceptual principle of parsimony, i.e. Occam's Razor, assuming no more than necessary. The empirical adequacy of a theory is measured by the range of facts it claims to account for. There is therefore a tension between the parsimony principle and empirical adequacy. More assumptions would of course account for more facts, but the parsimony constraint specifically limits this option. Thus, we need to make additional assumptions just when all others fail.

In linguistic theory, expressions of natural language may be taken as abstract formal objects, and the distribution of the various elements constituting these objects are subject to general principles of grammar. Thus, it may very well turn out, as it often does, that superficially very different facts are subject to the same grammatical principle. To illustrate this point, consider the examples in (1) and (2):

(1) a. John was told that Mary would be promoted.

(English)

b. John seemed to be very tired.

c. They expected John to be very tired.

d. It would be undesirable for there to be a riot.

(2) a. *It was told John that Mary would be promoted.

b. *It seemed John to be very tired.

c. *It was expected John to be very tired.

d. *It would be undesirable there to be a riot.

It is not obvious that the examples in (1) are related to each other or to those in (2) in the sense that they are subject to the same principle of grammar. We need not go into the details of what grammatical principle relating the examples in (1) and how it relates them to those in (2) (cf. Rouveret and Vergnaud 1980, Chomsky 1981 for an account in terms of Case theory). The point I would like to make here is more general: a theory relying on some abstract principle of grammar to explain the grammaticality of the examples in (1) and the ungrammaticality of those in (2) makes further empirical claims, namely, there cannot be a language or dialect of English admitting the examples in (3) as all grammatical:

(3) a. John was told that Mary would be promoted.

(Pscudo-English)

b. John seemed to be very tired.

c. It was expected John to be very tired.

d. It would be undesirable there to be a riot.

Nor can there be a language or dialect of English with the grammatical patterns in (4): 
(4) a. *They expected John to be very tired.

b. *It would be undesirable for there to be a riot.

c. It was told John that Mary would be promoted.

d. It seemed John to be very tired.

These are but two of the many logically possible languages or dialects which are excluded in principle by linguistic theory. The reason behind it is fairly simple. If the examples in (1) are permitted but those in (2) are ruled out by the same grammatical principle, then it is not possible, in principle, for a language with the same principle to partially permit or exclude them.

We may never know whether this empirical claim is true, for even if we cannot find a language allowing all the examples in (3) or having the grammatical patterns in (4), it does not mean that the empirical predictions of linguistic theory can never be verified. We can show that it is false if we can exhibit a language permitting the examples in (3) or one having the grammatical patterns in (4). And this can be done if we look at a wide variety of languages. It is therefore clear that linguistic theory is more than a theory about abstract formal objects; it is also an empirical science.

It is uncontroversial that the linguistic system is consisted of several subsystems, each of which has its own units, structures, and principles regulating their distributions. For instance, the distribution of phrases is clearly different from that of affixation on adjectives, verbs or nouns. While there is some degree of mobility for phrases, the place where a particular affix occurs is generally fixed. As shown in the German examples in (5) and (6), phrases may sometimes switch places, but affixes never can:

(5) a. Die Frau wollte den Mann küssen.

the woman want the man kiss

'The woman wanted to kiss the man.'

b. Den Mann wollte die Frau küssen.

(6) a. Die Frau woll-te den Mann küss-en.

the woman want the man kiss

'The woman wanted to kiss the man.'

b. *Die Frau woll-en den Mann küss-te.

c. *Den Mann woll-en die Frau küss-te.

However, the elements belonging to each subsystem (structural units, sets of principles governing them, etc) are neither totally distinct nor unrelated to each other. Alongside cases like (5) and (6), where there seems to be no relation between the mobility of phrases and the fixed order of affixes, i.e. phrases may appear in different places regardless of the fixed positions of the affixes, there are other cases where units of one subsystem co-incides with those of another. For instance, syntactic constituency often co-incides with phonological constituency in many cases. Thus, it is more natural to have an intonation break (indicated by a \#) at the edge of a syntactic constituent than at the middle of it, as shown by the contrast in (7):

(7) a. [ every student $] \#$ is coming to the party.

(English)

b. ?? [ every\#student ] is coming to the party. 
The examples in (7) therefore show the relation between syntax and phonology subsystems of the grammar. ${ }^{1}$ We may then take this and other similar relations to fall under the explanatory adequacy constraint on linguistic theory. That is, to the extent that it is possible, structural units and conditions governing them in one subsystem should have a bearing on those of another. This constraint would in effect mark a certain class of analyses as implausible, if not impossible in principle.

In short, we have three general constraints on linguistic theory: (i) The parsimony constraint: Occam's Razor (as few assumptions as possible), (ii) empirical coverage (the range of facts that the analysis can account for), (iii) explanatory adequacy (why should it be that the assumptions under (i) accounting for the facts under (ii) the way they are? More concretly, are there other facts in the grammar bearing on the analysis of a particular set of facts such that the properties of the latter set of facts must hold?). In this approach, then, properties of one linguistic entity in one subsystem of the grammar may have consequences for other subsystems, as we will see in some case studies of pronominal clitics.

\section{Pronominal clitics as objects of investigation}

Standard scientific practice requires that the object of investigation be well-defined. This seems to be an indispensible first step, for one has to say what it is that one wants to account for. However, various issues arise when we consider the conceptual basis of formal definitions. Pronominal clitics are a good case study illustrating this problem.

In the literature on pronominal clitics since Kayne (1975) and Zwicky (1977), it is commonly assumed that the list in (8) or some version of it contains the defining properties of pronominal clitics:

I Apparently there are occasional mismatches between syntactic and phonological constituents. The phonological property of the possessive marker 's and the reduced auxiliary $s$ for is and has in English is commonly taken to be a typical case of syntax/phonology mismatch. Voicing assimilation and vowel epenthesis apply to the $s$ even though it does not form a morphosyntactic constituent with the preceding element, in contrast with the plural $s$ :

(i) The Queen of England' [z] hat; the Queen of Egypt' [s] hat; the Queen of Franc' $[i z]$ hat.

(ii) John'[z]/Kate'[s]/Bruc'[iz] coming to the party; John'[z]/Kate'[s]/Bruc'[iz] left the party.

(iii) Land[z]; Mate[s]; Juic[iz]

While it is clear that the morphosyntactic relation involving the $s$ in (i) and (ii) differs from that in (iii), it does not seem compelling enough to completely obliterate the relation between syntax and phonology, cf. the syntax/phonology relation in (7). In the view in which linguistic structures are derived via a successive steps of computation (Chomsky 1995, 1999), it is imaginable that the syntax/phonology relation holds up to some point in the derivation, after which some phonological rules may apply to the syntactic representation. Along these lines, the facts in (i)-(iii) may be accounted for by a voicing assimilation and vowel epenthesis rule that linearly applies to the $s$ and the preceding segment, the syntactic constituent boundary between the two being irrelevant. 
(8) a. Non-occurrence in argument positions.

b. Complementary distribution with full DP arguments.

c. No modification.

d. No conjunction.

e. No contrastive stress.

f. No use in isolation.

g. Occurrence in specific positions.

Thus, an element like the French expression la in (9) having all these properties would accordingly be considered a pronominal clitic (capital letters represent stress) :

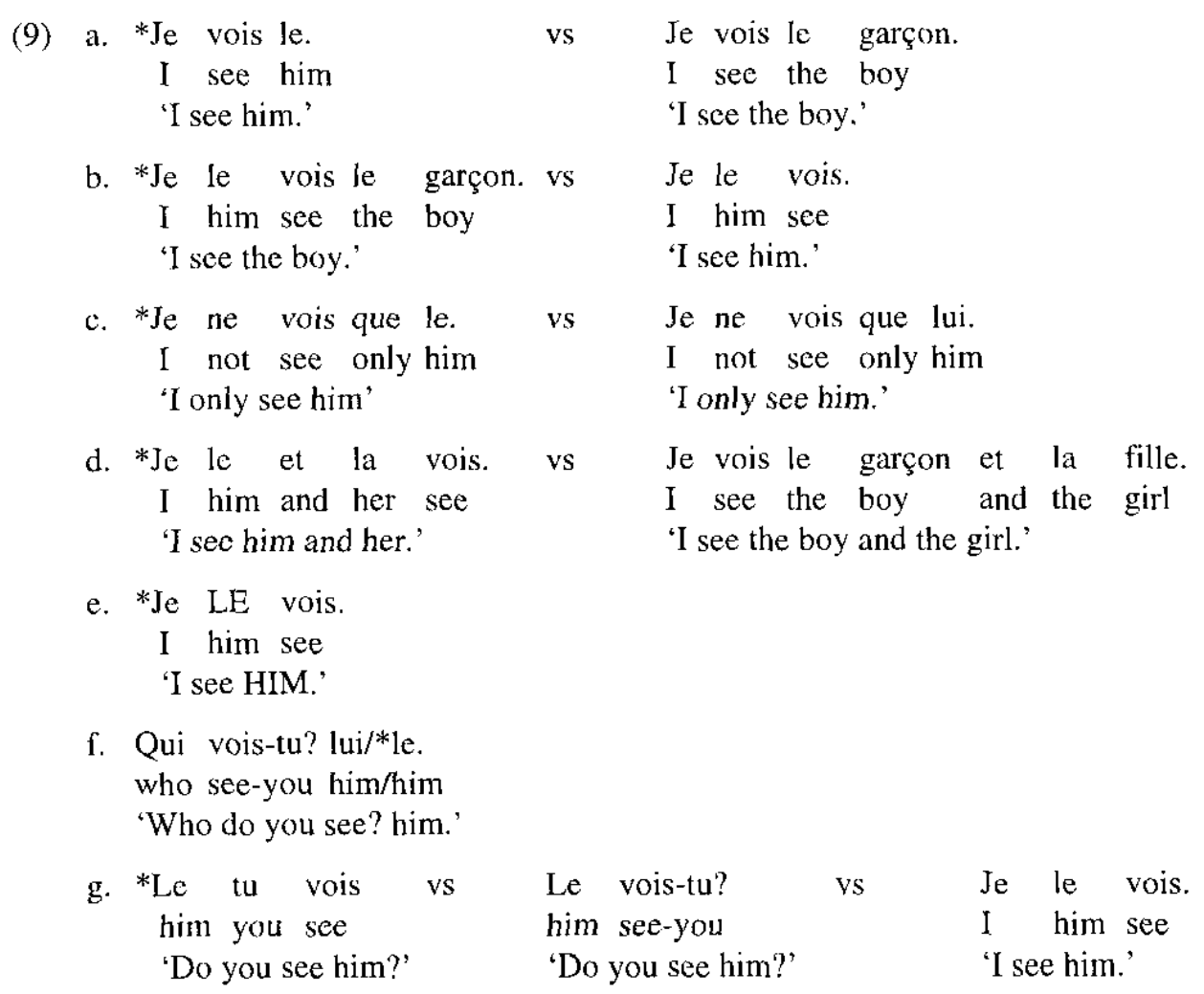

The expression lui in (9) would not be a pronominal clitic, since it lacks some of the properties in (8), e.g. (8c) and (8f) (cf. the examples in (9c) and (9f)).

The conceptual question that arises is whether we should take the properties enumerated in the list as defining what a pronominal clitic is. A priori, we can take the pronominal clitic as an independent category on a par with other categories like nouns, verbs, determiners, etc, and take the items in the list in (8) as parts of the definition of the pronominal clitic category. But the parsimony contraint requires that we posit no such category, if we can. Moreover, it would be an arbitrary decision to take the list in (8) as the defining properties of pronominal clitics, for we may ask why we should take these properties, instead of some other properties, to be the defining characteristics of pronominal clitics. Notice that to the extent that the properties in (8) hold, we have to explain why they do. That is, the properties in (8) need to be explained, whether we assume an independent category for pronominal clitics. Clearly, then, the assumption of an independent category for pronominal clitics does not contribute anything to the account of why the properties in (8) hold of some elements of the language. Moreover, 
by the explanatory adequacy constraint on theory, they must be shown to be related other independent principles of grammar. These lines of thought would lead us to a desirable result that the parsimony constraint on theory is satisfied, since there is no independent category for pronominal clitics.

The absence of a definition of what a pronominal clitic is may give the impression that we cannot provide an account for its grammatical properties, since we do not have a formal and precise definition of what it is that we want to account for. But this is only an apparent problem, for what needs to be explained is why the properties in (8) should hold of some particular elements of the language, not what expression is a pronominal clitic or why it is a pronominal clitic. In this light, consider Suñer's (1988) proposal that Spanish pronominal clitics are agreement markers on a par with subject agreement. All the properties in (8) hold of the Spanish la. It is easy to see how some though not all properties in (8) follow from treating it as an agreement marker. Take the properties in (8a), (8c)-(8f) for instance. The fact that a pronominal clitic is not in argument position (for DP), may not be modified or conjoined, may not bear contrastive stress or occur in isolation reduces to the same fact that subject agreement may not do so. To what degree the proposal can be maintained is a separate question, ${ }^{2}$ but clearly we need no independent category for pronominal clitics in order to account for why the properties in (8) hold of some particular elements of the language.

For descriptive purposes, it is convenient to have a name like pronominal clitic with which we can refer to elements like $l a$ in (9). The term would serve these purposes, as a convenient descriptive device. But it should be clear from the parsimony constraint perspective that the term pronominal clitic has no independent theoretical standing.

\section{Some specific properties of pronominal clitics}

In this section, we will look at some specific facts about pronominal clitics, and see how the general conceptual constraints limit the class of possible analyses for these. To illustrate their empirical ramifications, I will exhibit some logically possible languages but excluded by linguistic theory.

We will first consider some facts about participial agreement and auxiliary selection in Italian and French when a pronominal clitic occurs (section 4.1). I argue that

2 The property in $(8 \mathrm{~g})$ is a most serious problem for treating pronominal clitics as agreement markers on a par with subject agreement. In contrast with subject agreement, which occur in one fixed position, pronominal clitics may sometimes appear different positions:

(i) a. Te la quier-o enseñar.

(Spanish) you her want.1SG show

'I want to show her to you.'

b. *'Te la quier enseñar-o.

c. Quier-o enseñar-te-la.

If object pronominal clitics are agreement markers just like subject agreement, then there is no reason why they can appear on the non-finite verb enseñar 'to show' in (i), but subject agreement cannot. 
However, when we consider other facts about agreement, it becomes clear that the Spec-head relation does not always hold of the agreeing elements. Adnominal agreement and some instances of secondary predication are cases in point:

(15) a. Una signora simpatica/*simpatico

(Italian)

a woman sympathetic.FEM/sympathetic.MASC

'A sympathetic woman.'

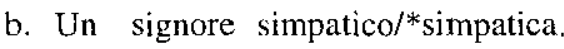

a man sympathetic.MASC/sympathetic.FEM

'A sympathetic man.'

(16) a. Inquieta/*inquieto, Maria ha telefonato a Gianni. worried.FEM/worried.MASC Maria have telefone to Gianni 'Worried, Marie called Gianni.'

b. Inquieto/*inquieta, Gianni ha telefonato a Maria worried.MAS/worried.FEM Gianni have telefone to Maria 'Worried, Gianni called Marie.'

There is no reason to believe that the structure of the examples in (15) are more complex than those in (17) (cf. Kayne 1994 for an alternative view), where the Spechead relation fails to hold of the agreeing elements (simpatica/simpatico and signora/signore in (15), and inquieta/inquieto and Maria/Gianni in (16)):

(17) a. [DP una $\left[_{\mathrm{NP}}\left[\left[_{\mathrm{NP}}\right.\right.\right.$ signora $]\left[\left[_{\mathrm{AP}}\right.\right.$ simpatica $\left.\left.]\right]\right]$

b. [IP [AP inquieta ] [iP Maria ha telefonato a Gianni ]]]

Neither the predicate nor the phrase with which it agrees are in the Spec position of the other. The APs in (17) are most plausibly adjuncts to the NP and IP respectively. Kayne's account of participial agreement clearly does not carry over to cases like (15) and (16). In this sense, it is empirically limited, and hence explanatorily unsatisfying.

The relevant structural difference between (10a) and (10b) is that in (10b) the full DP is in object position, i.e. in the VP-projection of the predicate, as in (18b), while the clitic in (10a) with which the predicate agrees is clearly outside the VP, as in (18a):

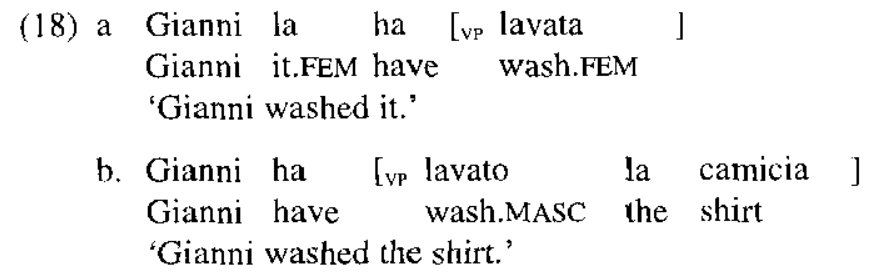

The structures in (18a) and (17), where there is agreement (with the participle and the adjective respectively), differ from the structure in (18b), where there is no agreement, in that the projection of the agreeing predicate does not contain the phrase with which it agrees. It is thus reasonable to bring this difference to bear on the agreement difference. Agreement between a DP and a predicate is possible when the DP is not contained in the projection of the predicate. 
(28) a. Maria ¿/*ha bell-a/*bell-o.

Maria be/have pretty.FEM/pretty.MASC

'Maria is pretty.'

b. Piero ì/*ha piccol-o/*piccol-a.

Piere be/have small.MASC/small.FEM

'Piero is small.'

(29) a. Essa è/*ha stata lavata.

it.FEM be/have be wash.FEM

'It has been washed.'

b. Esso è/*ha stata lavato.

it.MASC he/have be wash.MASC

'It has been washed.'

The examples in (28)-(29) show clearly that when the predicate agrees with the subject, then the auxiliary must be the be-type, not the have-type. We will see presently how this bears on the occurrence of the $b e$-auxiliary when the accusative object clitic pronoun is a reflexive.

In $(27 \mathrm{~b})$, the accusative object reflexive clitic pronoun agrees with the participle, ${ }^{6}$ just like any other accusative object pronominal clitics. The crucial fact is that the reflexive is bound by the subject, and the two agree (here, in person). The combination of these two facts result in the predicate agreeing with the subject. And we know from (28)-(29), quite independently, that the auxiliary co-occurring with a predicate agreeing with the subject must be the be-type, not the have-type. In $(27 \mathrm{a})$, the participle agrees with the accusative object clitic pronoun in number and gender (here, feminine). The be-auxiliary is impossible since it would require that the participle agree with the subject in number and gender (here, masculine). Obviously, the participle cannot carry the two (different) agreement morphologies at the same time.

"It is conceivable that participial agreement with reflexive clitics is independent from participial agreement with accusative clitics. Dative clitic pronouns show agreement with the participle just in casc they are interpreted as having the same reference as the subject:

(i) a. (loro) ci hanno telefonato/*telefonati.

they 1PL have.3PL telephone/telephone.PL

'They called us.'

b. (noi) ci siamo telefonati $/ *$ telefonato.

we $1 \mathrm{PL}$ be.1PL telephone.PL/telephone.

'We called ourselves/each other.'

In (ia), the participle does not agree with the subject. Thus, the agreement in (ib) must have something to do with the dative being interpreted as having the same reference as the subject. Note, however, first and second person non-subject clitic pronouns are not syntactically reflexive; they need not to be bound by a subject, cf. (ia), in contrast with the third person clitic pronoun si, which is syntactically reflexive, and hence must be bound:

(ii) a. (loro) si sono telefonati $/ *$ telefonato.

they self.3 be.3PL telephone.PL/telephone.

'They called themselves/each other.'

b. *(noi) si siamo/abbiami telefonati/telefonato.

we self.3 be.1PL/have.1PL telephone.PL/telephone.

'We called themselves/each other.'

It is not clear whether there are other facts bearing the agreement patterns in (i). 
In sum, it is not the reflexive/non-reflexive difference itself that explains why the auxiliary in (27b) must be the be-type, not the have-type. Rather, the difference has syntactic correlates that bear on agreement. A predicate agreeing with a reflexive object pronoun bound by the subject would end up agreeing with the subject, and the auxiliary co-occurring with a predicate agreeing with the subject cannot be the have-type, but must be the be-type. Thus, the occurrence of the be-auxiliary in (27b) is not an isolated syntactic fact about reflexive object pronominal clitics, but is related to the predicative adjective agreement in (28) and passive in (29).

Again, if linguistic theory is correct in that auxiliary selection, participial agreement with object clitics, predicate adjectives and passive, although superficially different, are different facets of the same phenomenon, then the empirical implication is that there cannot be a language in which auxiliary selection and agreement are not the same in all three constructions. For instance, one such impossible language or dialect of Italian would have the grammatical patterns in (30), where the be-type auxiliary co-occurs with predicate adjective agreement and in the construction with object pronominal clitics, but the have-type auxiliary occurs in passive without agreement with the subject:

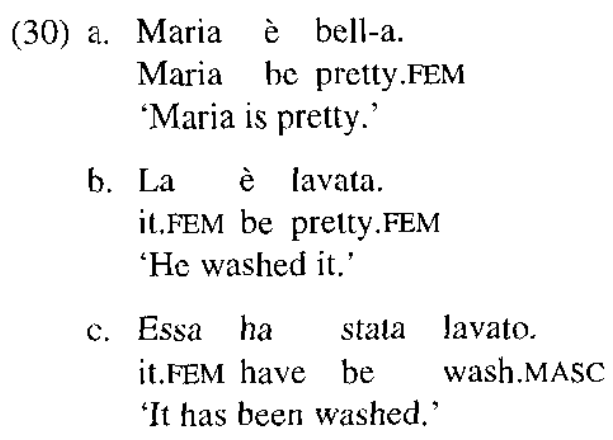

(Pseudo-Italian)

Nor can there be a language or dialect of Italian with the grammatical patterns in (31), where the be-type auxiliary appears in passive without participial agreement, and the have-type auxiliary occurs with an agreeing predicate adjective and with a non-agreeing participle:

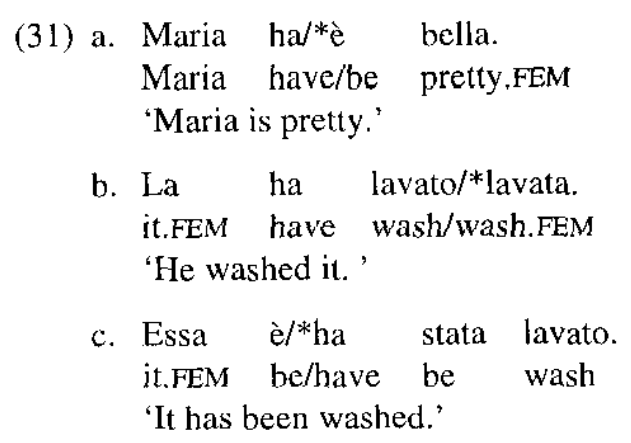

(Pseudo-Italian)

The examples in (30)-(31) are but two among many logically possible combinations that are excluded by linguistic theory as impossible grammatical patterns of language (cf. footnote 3 , however).

Two issues ensue: (i) is the empirical implication true? and (ii) if it is true, then why should it be? As discussed in section 1, it is difficult to settle the answer to (i) 
positively with certainty, for practical reasons. We probably cannot check all languages, those that still exist or used to exist but have died out, to see whether the implication is true. However, (i) can in principle be falsified if we can show a language with a combination of agreement properties that is excluded by linguistic theory, e.g. one that has the grammatical patterns in (30) or (31). It is in the latter case that we can see the empirical bearing of linguistic theory. The answer to (ii) is rather straightforward from the perspective of linguistic theory. To the extent that the empirical implication is true, it must be so since the grammatical principles underlying auxiliary selection and agreement are the same in the three constructions.

\subsection{Some phonological properties of Italian clitics}

Typically lacking stress, pronominal clitics cannot stand on their own. They must be integrated in an adjacent prosodic unit, and often exhibit specific phonological properties that are also observed with other prosodic units like the prosodic word (henceforth p-word), a phonological unit bearing stress.

The question that arises is whether pronominal clitics are prosodic units of some sort on a par with other independently established prosodic units like the p-word, or whether they are simply integrated in an independent prosodic unit, and hence does not belong to the prosodic hierarchy consisting of the syllable, the mora, the foot, the $p$ word, the phonological phrase (p-phrase) and intonational phrase (i-phrase). The issue is of particular interest if there is some relation between phonological structure and morphosyntactic structures. Should pronominal clitics turn out to constitute independent prosodic units and are placed in the prosodic hierarchy, then morphological and syntactic structures containing pronominal clitics may have to reflect this prosodic unit, i.e. we may have to posit some morphological or syntactic unit of sorts corresponding to the prosodic units exclusively comprising the clitics. We thus see how phonology may haye correlates with morphology and syntax.

Selkirk (1980) suggests that a clitic and its host form a p-word, while Nespor (1984) argues that they are themselves independent prosodic units, which she calls clitic group, distinct from other prosodic units like p-word, p-phrase and i-phrase. There are several phonological facts of Italian that appear to be relevant to the issue of whether pronominal clitics form an independent prosodic unit. First, Nespor and Vogel (1982) show that in Standard Italian, a sequence of two p-words, which may independently bear stress, has primary stress on the second p-word:

(32) a. Mezzo giórno. middle day 'Mid-day'

b. Senza tétto. without roof 'Without home, homeless'

But in a sequence consisting of clitics and their host the stress falls on the host regardless of the position of the clitics: 
(33) a. Glie-lo diránno

(Italian)

him-it say

'They will say it to him'

b. Dicéndo-glie-lo.

tell-him-it

'Telling him it'

Apparently, then, clitics do not behave like p-words.

Second, the vowel truncation rule optionally deletes the vowel of the last syllable of a p-word containing a single verb, when it is followed by another p-word beginning with a consonant:

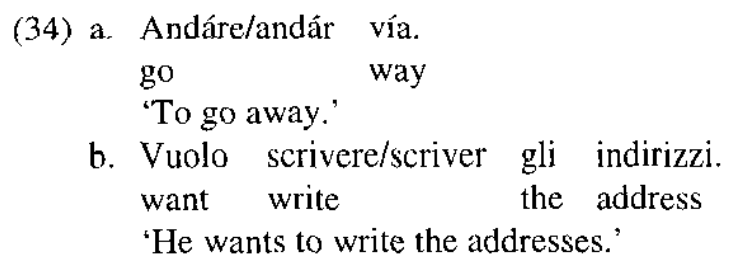

(Italian)

But it obligatorily deletes the vowel of the verb if it is followed by a pronominal clitic:

(35)
a. Andár/*andáre ci
go there
'To go there.'
b. Dár/*dáre gli.
give them
'To give them.'

Note the difference between the determiner $g l i$ 'the' in (34b), and the pronominal clitic $g l i$ 'them' in (35b). In (34b), gli is part of the following p-word that includes the noun indirizzi 'address', so there is a p-word boundary separating gli and the preceding verb scrivere 'to write'. In (35b), however, the pronominal clitic gli is in the p-word containing the verb, with no p-word boundary separating the two:

(36) a. [ scrivere $]_{\mathrm{PW}}[\text { gli indirizzi }]_{\mathrm{PW}} \Rightarrow>[\text { scriver }]_{\mathrm{PW}}[\text { gli indirizzi }]_{\mathrm{PW}}$

(Italian)

b. $[\text { dar }- \text { gli }]_{\mathrm{PW}}=>[\text { dar-gli }]_{\mathrm{PW}}$

The fact that the vowel of the verb in (36a) is optionally deleted, but that in (36b) is obligatorily deleted can be accounted for by assuming that the truncation rule optionally applies across a p-word boundary, but obligatorily within a p-word. In other words, the vowel deletion rule requires that the clitic in (36b) be treated as a non-p-word.

Third, the rule of Raddoppiamento Sintattico (RS) geminates the initial consonant of a p-word, if it is immediately preceded by a stressed syllable belonging to another $\mathrm{p}$ word (Nespor and Vogel 1982) (gemination is represented by a : after the geminated consonant):

(37) a. Sará [p:]artito.

(Italian)

be leave

'He will have left'

b. Súlb/*b:]ito.

'Immediately' 
But the RS rule also applies to a sequence consisting of a verb and a following clitic, treating the two as if they do not form a prosodic unit:

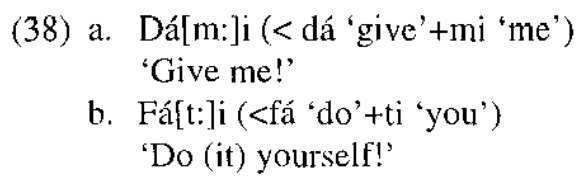

(Italian)

If the pronominal clitics in (38) were part of the p-word containing the preceding verb, then we should expect the RS rule not to apply, just as it does not in (37b). But we know from the facts about stress and the vowel truncation rule above that the clitic itself is not a p-word. The conclusion is then that the clitic in (38) is a different prosodic unit from p-word.

Fourth, the rule of intervocalic s-voicing in Northern Italian dialects applies to derived lexical items as in (39a)-(39b) and to underived lexical items as well as in (39c), but it never applies to an $s$ if the vowel to its left belongs to an independent morphological unit, as in (39d):

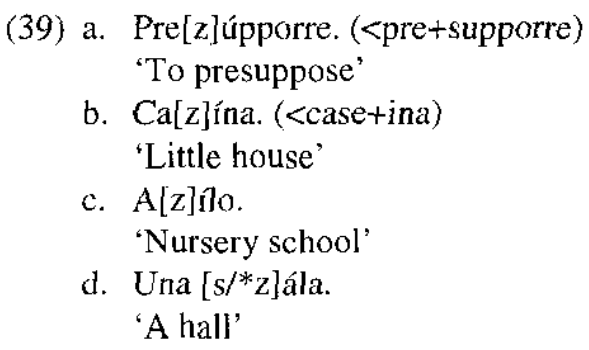

Suppose the rule of intervocalic s-voicing applies to an $s$ if it and the two vowels flanking its two sides are within one p-word. We can now distinguish (39a)-(39c) on the one hand and (39d) on the other, if in (39d), the determiner una ' $a$ ' is not part of the following pword. The rule apparently treats the clitic as if it is not part of an adjacent p-word:

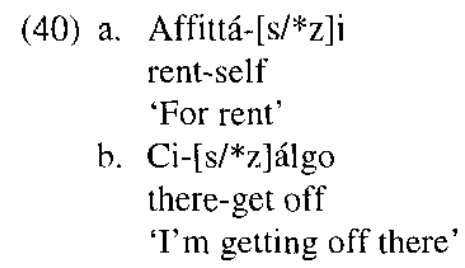

The examples in (40) thus appear to suggest, again, that the clitic is of a different prosodic category from $p$-word; perhaps they form a clitic group as Nespor suggests.

If this is correct, then it may have ramifications for the morphological and syntactic analyses of clitics; the morphological and syntactic representation involving clitics may have to be such that part of it corresponds to the prosodic unit clitic group. As it has farreaching consequences, we need to closely examine the justification of the clitic group.

On closer look, it turns out that the phonological facts discussed above do not warrant clitic group as an independent prosodic unit. What the stress facts in (33) and those about vowel truncation in (35) show is that the pronominal clitics are not p-words. It does not follow from that, however, that they form an independent prosodic unit 
called clitic group. These facts are consistent with the pronominal clitics being part of an adjacent p-word; that is, the pronominal clitic is included in the p-word. From this perspective, the RS rule and the intervocalic s-voicing rule seem problematic, cf. the examples in (39) and (40). These rules appear to treat the pronominal clitics as if they are not part of an adjacent p-word. Before we try to reconcile this apparent contradiction, let us consider the question of whether we need the notion of clitic group as an independent prosodic unit to account for these various facts.

The assumption that pronominal clitics form a clitic group does not seem to provide much of an explanation for the facts in (39) and (40), for we may ask why the RS rule and the intervocalic s-voicing rule should treat p-words and clitic groups alike, if the clitic group is indeed a prosodic unit different from the p-word. In fact, we may wonder whether it is the formulations of the rules for these various phonological facts that lead to the assumption of the prosodic unit clitic group. So it is quite conceivable that we need not appeal to clitic group with some alternative formulations of the rules.

Using phonological facts of several dialects of Italian, Peperkamp (1996) argues that there is no need for an independent prosodic unit like clitic group, and that pronominal clitics can be integrated into an adjacent prosodic unit by adjoining to a pword, incorporating into a phonological phrase or incorporating into a p-word:

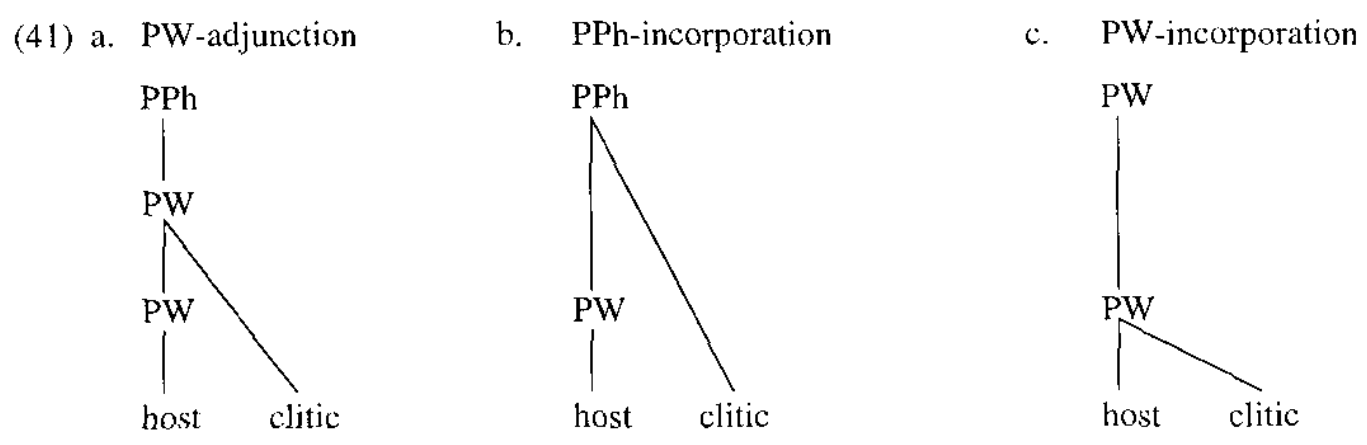

Although she does not give an account for these various facts about pronominal clitics in Standard Italian, it is conceivable that the examples with pronominal clitics may have the PW-adjunction structure.

Suppose the pronominal clitic in (33) is adjoined to a p-word, as in (42), and the stress rule operates on a sequence of two p-words shifting primary stress to the second p-word:

(42) a.

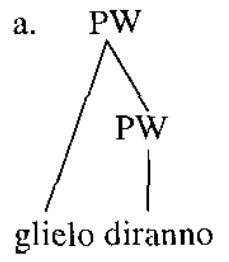

b.

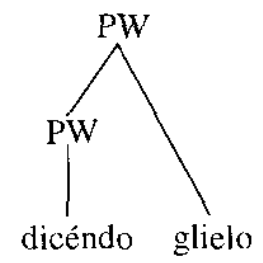

7 The PW-adjunction structure seems most plausible for the analysis in the text, since adjunction structure is independently assumed for syntax (ef. the discussion of (44)-(48) below). As far as I can tell, the PW-incorporation structure can also account for these facts, pcrhaps with different formulations of the various rules. The issue is whether there is any syntactic or morphological correlate of the PW-incorporation structure. 
The reason why pronominal clitics do not affect stress in Standard Italian is now straightforward. In (42), the pronominal clitics is adjoined to the verb, a p-word; it is therefore part of the p-word. Since the two do not constitute a sequence of p-words, they are not subject to the stress rule. By contrast, the examples in (32) are sequences of $\mathrm{p}$ words, as shown in (43), and hence are subject to the stress rule, which shifts the primary stress to the second $\mathrm{p}$-word:

(43) a.

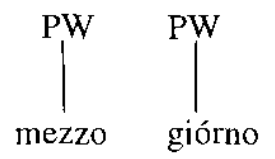

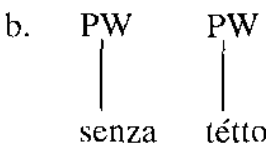

Similarly, suppose the examples in (35) have the prosodic structures in (44), where the two occurrences of PW are taken to be two segments of the same prosodic category, the same assumption made for syntactic structures (cf. May 1985):

(44) a.

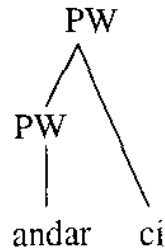

b.

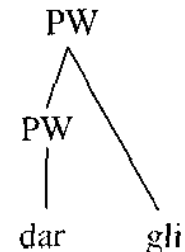

Crucially, the lower occurrence of PW in (44) does constitute a p-word; it is only a part of the whole p-word adjunction structure. We can formulate the vowel truncation rule as obligatorily deleting the final vowel of a verb if it is not at the edge of a p-word, and optionally otherwise. The examples in (34) can now be distinguished from those in (35).

In their prosodic structures in (44) for the examples in (35), the final vowel of the verb is not at the edge of a p-word, for the verb lies entirely within a larger p-word adjunction structure. The final vowel of the verb is therefore obligatorily deleted. By contrast, in the prosodic structure in (36a) for the example in (34b), and in a similar structure for the example in (34a), the final vowel of the verb is at the edge of a p-word. It is therefore only optionally deleted.

Turning now to the RS rule, and consider the prosodic structures in (45) for the examples in (38):

(45) a.

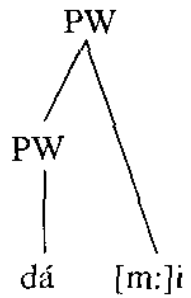

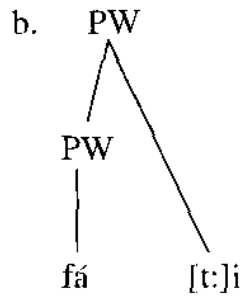

Suppose, contrary to the earlier formulation of the RS rule, we now state it as a rule applying to the initial consonant of an expression if it is preceded by a stressed syllable and the two are separated by (at least) one p-word segment. So formulated, the RS rule would apply to the structures in (45) as well as to the structure in (46a) for the example in (37a), but it does not apply to the structure in (46b) for the example in (37b): 

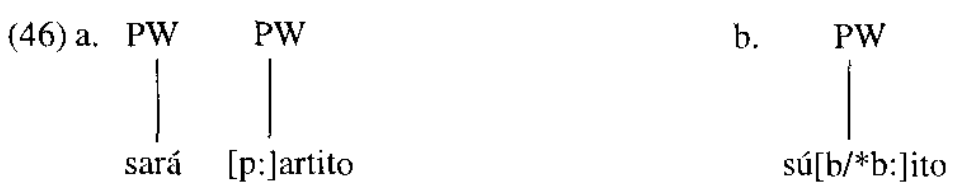

In (45) and (46a), there is at least one p-word segment separating a stressed syllable and the following consonant, while in (46b), there is no p-word segment separating the two.

Along the same lines, the intervocalic s-voicing rule, stated as a rule applying to an $s$ if it is not separated by a p-word segment, would fail to apply to the examples in (40), whose prosodic structures are given in (47):

(47) a.

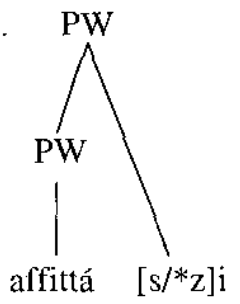

b.

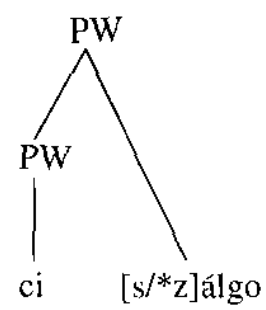

By contrast, in the prosodic structures for the examples in (39) given in (48), the $s$ is subject to the intervocalic s-voicing rule, since there is no p-word segment separating the $s$ and the following stressed syllable:
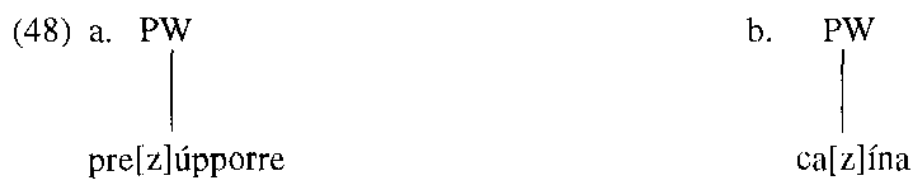

Without the clitic group as an independent prosodic unit, two desirable consequences follow directly. First, for the phonology, there is no need to assume the prosodic unit clitic group. Second, for the interface with morphology and syntax, there is no need to posit some morphological or syntactic unit corresponding to the clitic group. We can thus preserve the corresponding units in phonology and morphosyntax; roughly, p-words correspond to morphosyntactic units like heads and p-phrases and i-phrases correspond to syntactic phrases and larger constituents (cf. footnote 1, however). Both consequences are desirable from the perspective of the parsimony constraint.

In the alternative account without appealing to the notion of clitic group as an independent prosodic unit, the pronominal clitics are part of a $\mathrm{p}$-word. We should then expect the complex consisting of a verb and a clitic, a p-word, which corresponds to a morphosyntax unit $\mathrm{X}^{\circ}$ elsewhere, to behave as a morphosyntactic unit as well. This seems to be largely correct. The pronominal clitic, at least in Italian, seems to form a morphosyntactic unit with the verb, e.g. the pronominal clitic moves together with the verb wherever the verb moves. 


\subsection{The clitic-doubling construction}

In Rumanian and some dialects of Spanish, a pronominal clitic may co-occur with a full DP object in argument position, giving rise to what is known as the clitic-doubling construction in (49)-(50) (We will later discuss the occurrence of $a$ in Spanish or pe in Rumanian before the direct object):

(49) a. Lo vimos a Juan.

him see.lPL to Juan

'We saw Juan.'

b. Le di un anillo a María.

her give.1SG a ring to María

'I gave Maria a ring.'

(50) a. L'am vazut pe Jon.

him-have see to Jon

'I saw Jon.'

b. I-am dat cartea lui Popescu. him-have give book him Popescu 'I gave his book to Popescu.'

However, the occurrence of a doubling pronominal clitic is excluded if the full DP is in some intuitive sense indefinite or non-specific (Suñer 1988:396, Steriade 1980:283):

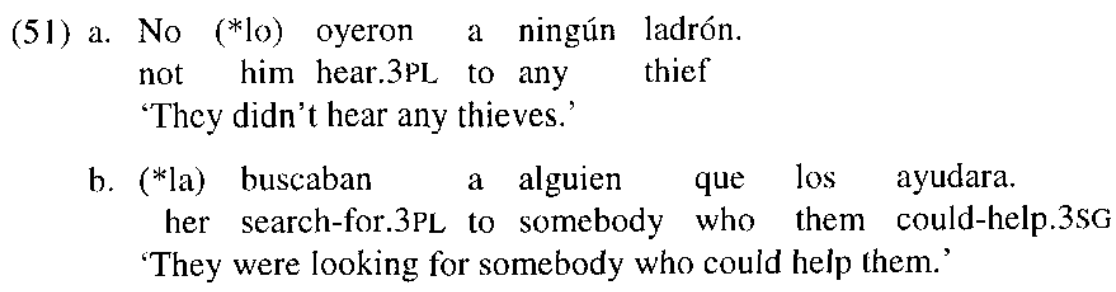

b. (*la) buscaban a alguien que los ayudara. her search-for.3PL to somebody who them could-help.3SG 'They were looking for somebody who could help them.'

(52) a. (*i)-am văzut cîinele lui Popescu. him-I-have seen the dog him Popescu 'I saw Popescu's dog.'

b. (*le) caut un bacătar.

him I-look-for a cook

'I'm looking for a cook.'

In French or Italian, the clitic-doubling construction is simply impossible (the example in (52c) is grammatical with a pause after the verb, cf. Lambrecht 1999 . We will return to this important fact below):

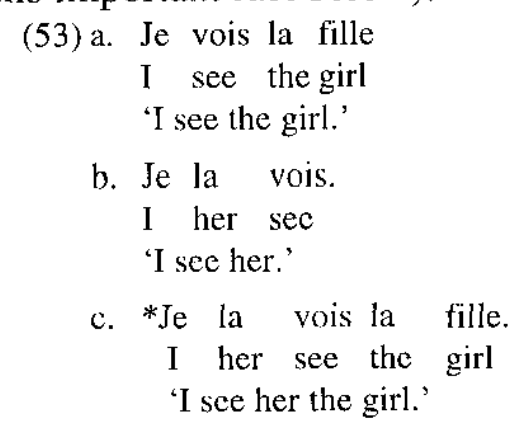




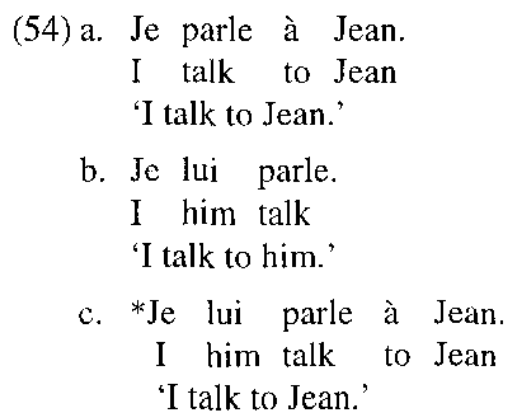

Given the explanatory adequacy constraint, we have to ask whether the grammatical contrast between the examples in (49)-(50) and those in (51)-(52) with respect to the presence of a clitic pronoun is related to any other property that may explain why the contrast should hold. In the same vein, we can also raise the same question for the variations within Romance languages, i.e. whether there are other differences between Spanish and Rumanian on the one hand, and French and Italian on the other that bear on their difference with respect to the clitic-doubling construction.

Intuitively, pronouns stand for full DP arguments. The ungrammaticality of the French example in (53c) is thus unsurprising. Either the pronoun or the full DP argument, but not both at the same time, may satisfy the requirement of a transitive verb that there be an object. The same explanation carries straightforwardly over to the ungrammaticality of the example in (54c). The Spanish and Rumanian sentences in (49) and (50) are problematic, however, since the same reasoning should lead us to expect, incorrectly, that they are ungrammatical as well, just like the French examples.

The impossible appearance of a pronominal clitic in (51) and (52) is similarly a problem, for there seems to be no reason why the definite/specific vs indefinite/non-specific distinction should bear on the satisfaction of the subcategorization property of the verb. The clitic-doubling construction therefore raises a host of syntactic and semantic issues, not only for the analysis of the construction in languages that (sometimes) allow it, but also for the account of the variations in the closely related languages.

\subsubsection{The position of the clitic-doubled DP}

Essentially following Sportiche (1992), Uriagereka (1995) suggests that the clitic pronoun generally heads a projection in the direct object position, and head-moves to its surface position, as in (55a). The clitic-doubling construction essentially has the same structure, except that the Spec position of the direct object is occupied by the doubled full DP, as in (55b):

(55) a. $\mathrm{Lo}_{i} \operatorname{vimos}\left[\mathrm{DP}\left[t_{i}[\mathrm{NP}\right.\right.$ pro $\left.\left.]\right]\right]$ (Spanish)

him see

'We see him.'

b. $\operatorname{Lo}_{i}$ vimos $\left[{ }_{\mathrm{oP}}\right.$ a $\operatorname{Juan}\left[t_{i}\left[\left[_{\mathrm{NP}}\right.\right.\right.$ pro $\left.\left.]\right]\right]$

him see to Juan

'We see Juan.' 
There are problematic aspects of the analysis in (55) whose details I cannot go into here, e.g. there seems to be no independent evidence for the doubled full DP appearing in the Spec position of a DP headed by the pronominal clitic, or for the pronominal clitic taking a complement (cf. Postal's (1969) idea that pronouns are intransitive determiners). What I like to do here is to discuss the empirical predictions of the analysis in (55), and to bring various independent facts to bear on the analysis.

It is clear that if the derivation and representation of the sort in (55) is possible, then we would expect the pronominal clitic to be able to double all types of full DPs, in particular, negative quantifiers. The grammatical contrast in (56) shows that the expectation is not borne out:

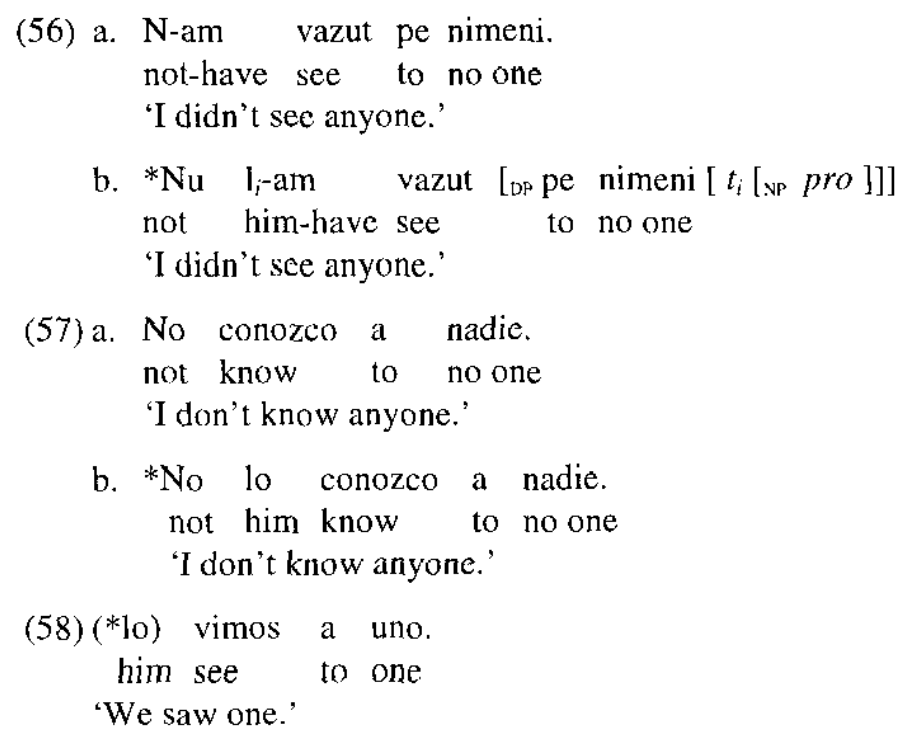
(Rumanian)

Steriade (1980) argues that the example in (56b), and by the same token those in (57b) and (58) as well (Uriagereka 1995), are independently excluded on semantic grounds. Specifically, the doubling clitic must be related to a definite/specific DP. As none of the full DPs to which the pronominal clitic is related is definite/specific, these examples are therefore ruled out semantically.

There are both empirical and conceptual problems with this explanation. Empirically, it seems to predict incorrectly that clitic pronouns may not be bound as variables. Negative quantifiers are plausibly indefinite, and hence may not serve as antecedents to clitic pronouns, if these are subject to the definiteness restriction. The expectation is again not borne out:

(59) Ningun estudiante quiere que su maestro lo vea en el bar. No student wants that his teacher him see in the bar 'No student wants his teacher to see him in the bar.'

A clitic pronoun may also be discourse-bound by a negative quantifier, showing again that it is generally not subject to a definiteness constraint:

\footnotetext{
(60) a. Que cosa no cree ningun estudiante que hara su maestro. (Spanish) which thing no think no student that will-do his teacher 'What does no student think that the teacher will do?'
} 
b. Pedir-le que suspenda la clase. ask-him that fail the class

'To ask him to fail the class.'

c. Llevar-lo a un bar. take-him to a bar

'To take him to a bar.'

Facts of the sorts in (59) and (60) are quite general, independently of the clitic-doubling construction and pronominal clitics. French does not have the clitic-doubling construction, but allows a clitic pronoun to be bound by an indefinite DP; in fact, the binder of the pronominal clitic need not even appear in the same sentence:

(61) Aucun étudiant ${ }_{i}$ ne pense que le professor lui donne un cadeau. (French) no student not thinks that the professor him give a present' 'No student $t_{i}$ thinks that the professor is giving him ${ }_{i}$ a present'

(62) a. Qu'est-ce que aucun étudiant ${ }_{i}$ pense que le professeur va faire? What-it that no student thinks that the professor go do 'What does no student thinks that the professor is going to do?'

b. Lui demander d'échouer à un examen.

him ask to-fail in a exam

'To ask him to fail an exam.'

The same facts hold of languages like English that have no clitic pronoun:

(63) No student $t_{i}$ thinks that the professor is giving himm ${ }_{i}$ a present.

(English)

(64) a. What does no boy; fail to forget?

b. $\mathrm{His}_{i}$ first dental appointment.

Therefore, there is no good reason to suppose that pronominal clitics are subject to the constraint that they be related to a definite DP. In other words, the proposed semantic constraint is descriptively inadequate.

Conceptually, Steriade and Uriagereka's accounts do not bring independent facts to bear on their explanations, and therefore are explanatorily inadequate. With this in mind, let us consider the examples in (65) and (66), which lack a doubling clitic:

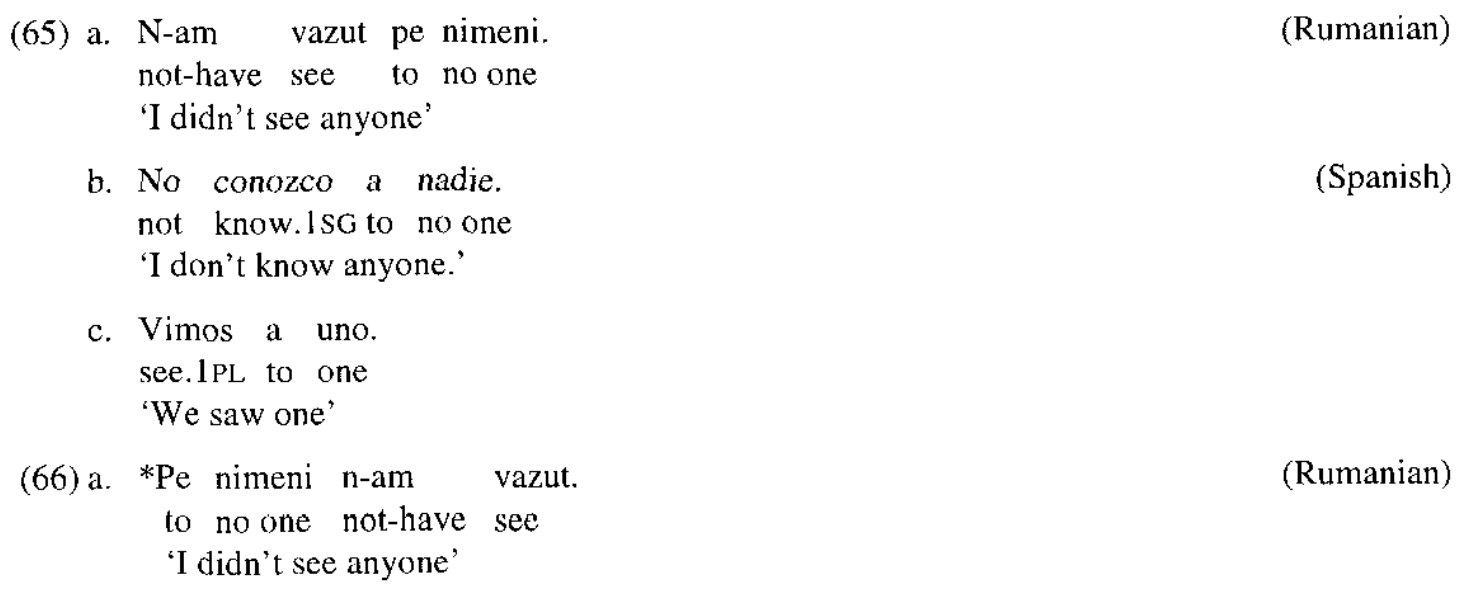




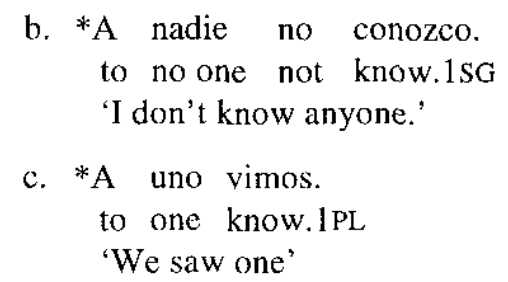

Clearly the direct object is in argument position in (65), but in non-argument position in (66). The same facts hold in English as well:

(67) a. I saw nobody yesterday.

b. *I saw yesterday nobody.

c. John, I saw yesterday.

d. *Nobody, I saw yesterday.

The grammatical contrast between (65) and (66) clearly shows that negative quantifiers may not appear in non-argument position. We can now relate the ungrammaticality of the examples in (56b) and (57b) to that of those in (66), if the clitic-doubled full DP in the clitic-doubling construction in fact occupies a non-argument position, a conclusion reached by Aoun (1981) and Hurtado (1984) on some other grounds.

As it turns out, facts about the clitic-doubling construction are rather complex. Speakers do not seem to have uniform judgments. While many find (68a) quite good (Franco 2000), they seem to disagree on (68b):

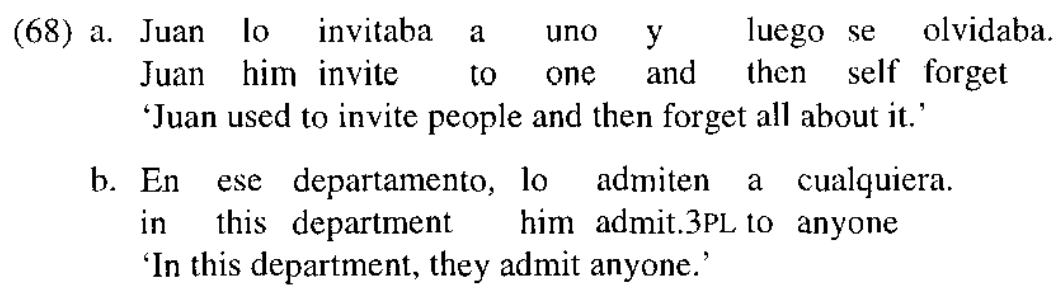

If uno 'one' in (68a), here interpreted as generic, is changed to una 'one', referring to some antecedent with (grammatical) feminine gender, the sentence becomes very bad (Luis Lopez-Carretero, personal communication). Nevertheless, to the extent that the clitic-doubling construction is good, the clitic-doubled full DP may appear in a nonargument position, with or without the clitic pronoun:

(69) A uno Juan (lo) invitaba y luego se olvidaba.

to one Juan him invite and then sclf forget

'Juan used to invite people and then forget all about it.'

Given that a uno 'to one' may appear in non-argument position in (69), it would not be too surprising that it may also do so in (68a).

Intonation is often brought up to argue that the clitic-doubled full DP is not in a non-argument position. It is often pointed out that in the clitic-doubling construction there is no intonational break before the clitic-doubled full DP, in contrast with the examples in (70), the same examples as in (53c) and (54c) but with an intonational break before the full DP in non-argument position, indicated orthographically by a comma: 
(70) a. Je la vois, la fille.

I her see the girl

'I see her, the girl.'

(French)

b. Je lui parle, à Jean.

I him talk, to Jean

'I talk to him, Jean,'

Hence, so the argument goes, the clitic-doubled full DP cannot be in non-argument position.

The argument is not very compelling, however. Non-subcategorized adverbials like those in (71) are clearly in non-argument position, but there need not be an intonational break before them:

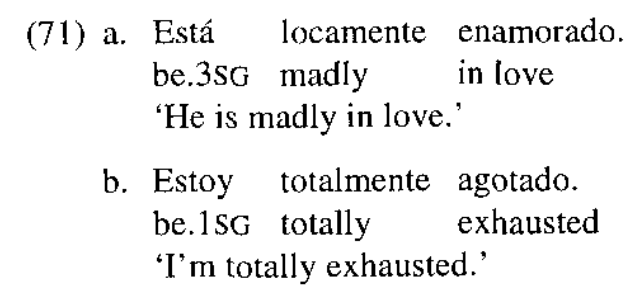

(72) a. Mergem duminică la ruine. will go sunday the ruins 'We'll go to the ruins on Sunday.'

(Spanish)

b. Maria e cu totul dezamăgită. Maria be with total disillusion 'Maria is completely disillusioned.'

Moreover, as there are many non-argument positions, so it is conceivable that the cliticdoubled full DP and those in (70) occupy different non-argument positions.

\subsubsection{The Case property of the clitic-doubled DP}

Returning now to the question of whether the apparent lack of the clitic-doubling construction in French and Italian is related to any other differences between them and Spanish and Rumanian. As mentioned above, a noticeable property of the cliticdoubling construction is the presence of an element preceding the clitic-doubled DP. It looks like a preposition that appears elsewhere ( $a$ in Spanish and $p e$ in Rumanian). Significantly, this preposition-like element may also precede the direct object without the clitic pronoun:

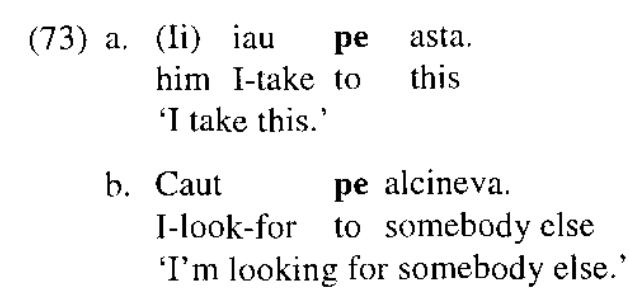


But as we can see in (77) and (78), the preposition $a$ or pe differs from that prededing a direct object full DP in that it has no restriction on the DP following it. It need not be definite/specific or have human reference. Despite this difference, one may still want to relate it to the preposition in some way. For instance, we may say that they are both Case-assigners.

Aoun (1979) and Borer (1984) suggest that quite generally the clitic pronoun on the verb absorbs Case. On this view, the presence of the preposition-like element $a$ or $p e$ is to Case-mark the DP that follows it. In the examples in (53), repeated in (79), if a pronominal clitic occurs, and hence absorbs Case for the direct object, the lack of a preposition-like element to Case-mark the DP direct object would lead to a violation of the Case Filter (Rouveret and Vergnaud 1980), which excludes overt DPs without Case:

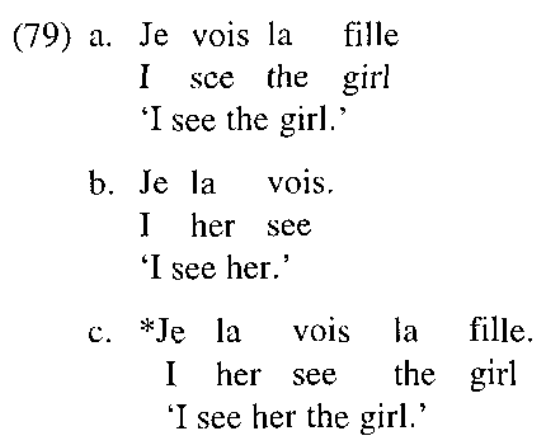

(French)

Suppose the Case-theoretic account for the clitic-doubling construction is correct, what kind of facts should we expect to see or not to see in Spanish and Rumanian?

If the clitic pronoun on the verb absorbs Case, and as a result the verb can no longer assign Case, then we should expect to see that in the absence of a clitic pronoun, the verb should be able to assign Case to the full DP in argument position. This is largely true, as shown in (80)-(81):

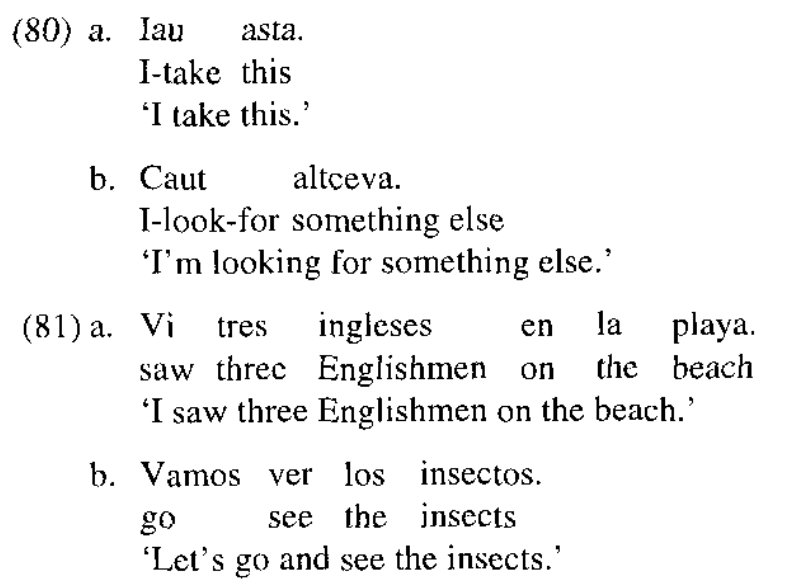

The problem is the examples in (73) and (74), however. Here, there is no Case-absorbing clitic pronoun on the verb. We should expect not to see the preposition-like element $a$ or pe in front of the direct object DP. These examples thus show that Case-assignment from the verb is independent of the preposition-like element $a$ or $p e$. 
Moreover, if the preposition-like element $a$ or $p e$ in the clitic-doubling construction is there to Case-mark the DP following it, Case to the DP being absorbed by the clitic pronoun, then we should expect this element to appear in other instances where Case is absorbed. The passive construction now becomes relevant. Recall the standard assumption that passive morphology on the verb absorbs Case; consequently, the verb can no long assign Case to the direct object in argument position (Aoun 1979, Chomsky 1981). The direct object of a passive verb therefore must move to subject position to get Case, to avoid a Case Filter violation:
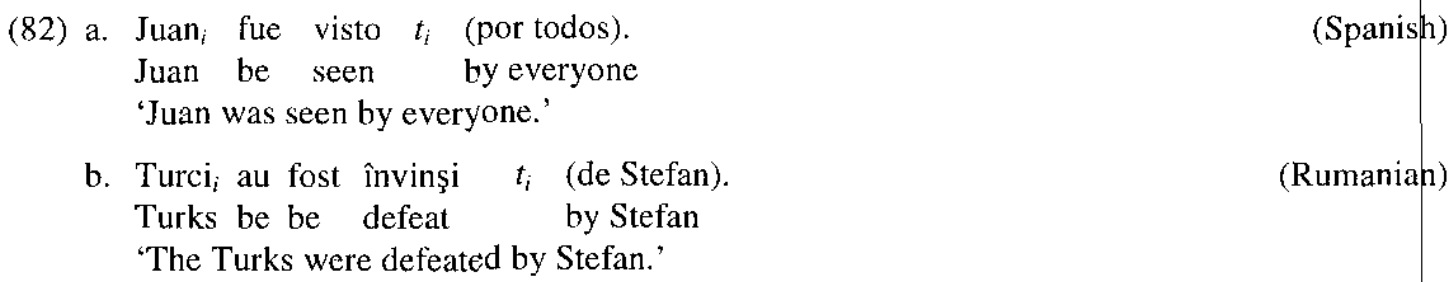

With respect to Case, then, the passive construction is completely parallel to the cliticdoubling construction.

But there are two facts showing that the two constructions do not have the same Case property. First, in contrast with the clitic-doubling construction, the passive construction does not allow a direct object to be Case-marked by the preposition-like element $a$ or pe:

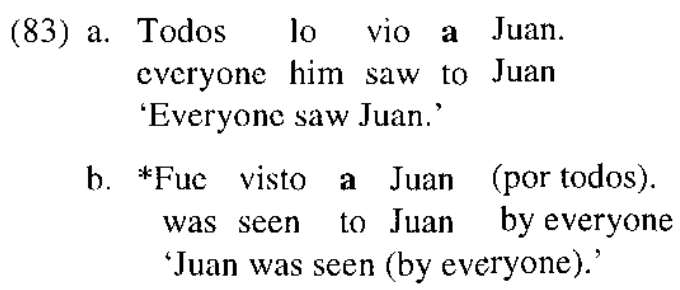

(84) a. Stefan î̀ învise pe turci. Stefan them defeated to Turks 'Stefan defeated the Turks.'
b. *Au fost pe turci (de Stefan). be defeated to Turks by Stefan 'The Turks were defeated by Stefan.'

Second, while Case-absorption by passive morphology results in the direct object moving to subject position to get Case, Case-absorption by a pronominal clitic never does. The examples in (85), though grammatical, do not have the interpretation in which the surface subject is understood to be the direct object of the verb, an interpretation derivable on a par with passive with the direct object moving to subject position:

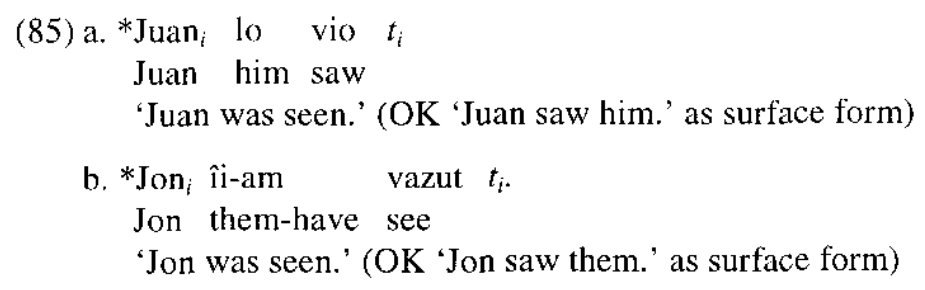


This is contrary to what we would expect if the clitic pronoun absorbs Case on a par with passive morphology. The clear difference between passive and the clitic-doubling construction thus shows that the Case-theoretic account for passive definitely cannot be extended to the clitic-doubling construction; therefore, there is no reason to assume that the presence of a preposition-like element $a$ or pe in the clitic-doubling construction has anything to do with Case.

Return now to the French examples in (70), repeated in (86). As already mentioned, these examples are grammatical with a pause before the full DP in argument position:

(86) a. Je la vois, la fille.

I her see the girl

'I see her, the girl.'

b. Je lui parle, à Jean.

I him talk to Jean

'I talk to him, Jean,'

In fact, examples like (86) are also possible with other phrasal categories. Milner (1978) gives many examples of PPs in the right periphery doubled by an adverbial en on the verb, very much like an accusative or dative pronominal clitic:

(87) a. Mon amie en revient samedi prochain, de Paris.

my friend from there come back Saturday next, from Paris

(French)

'My friend is coming back from Paris next Saturday.'

b. Cette amie en apporte au patron, des livres.

this friend of them bring to the boss of the books

'This friend is bringing some books to the boss.'

Apparently, the full DP in the right periphery in (86) is in non-argument position, just like the right-peripheral PPs in (87). From this perspective, the position of the cliticdoubled DP in (86) is thus very much like the Spanish $a$-phrase or Rumanian pe-phrase in the clitic-doubling construction; they all occur in non-argument positions, although not necessarily in the same positions (cf. the discussion surrounding (70)-(72)). If this is correct, then we can conclude that the French examples in (86) do not differ that much from the clitic-doubling construction in Spanish and Rumanian. The difference between them is rather minimal: there is a pause before the clitic-doubled full DP in argument position in French and Italian, but not in Spanish and Rumanian. The conclusion seems plausible. French, Italian, Spanish, and (to a lesser extent) Rumanian, are closely related languages. If we assimilated the French examples in (86) to the clitic-doubling construction in Spanish and Rumanian, then the difference among them would be accordingly reduced.

The conclusion that the preposition-like element $a$ in Spanish or pe in Rumanian appearing in front of a direct object is not related to Case does not reveal the grammatical principle underlying its properties, however. The difficulty here is two-fold. First, the distribution of this preposition-like element is very limited; it is the only element that may stand in front of a direct object. Second, DPs in other syntactic contexts are not subject to the conditions that the preposition-like element imposes on the following DP. It is therefore very difficult, if not impossible, to bring independent facts to bear. 


\section{Conclusion}

It is clear that once we delimit the confines of the general framework within which we carry out our investigations, certain classes of analyses lying outside the confines would be excluded as impossible explanations of the facts. However, the delimitation is not only conceptual, but also has empirical ramifications. The explanatory adequacy constraint requires that assumptions for some particular facts be brought to bear on other assumptions in the same subsystem of grammar as well as those in other subsystems. With this intimate connection, facts falling under the principles of some subsystem as well as those related to them in other substems must cluster together. A far-reaching empirical correlate of this is that there cannot be a language that has the same set of principles but allows a different set of facts.

In the discussion of the various properties of pronominal clitics, we did not formally define what a pronominal clitic is; evidently we do not need a formal definition of it in order to account for the properties associated with its distribution. It is the properties themselves that need to be accounted for, and a formal definition of pronominal clitics does not help. I should like to point out that the properties of pronominal clitics discussed above are but a few among their many properties, many of which are still fairly obscure (cf. footnotes 3 and 6 ). Their obscurity is not helped by the apparent lack of other elements having properties remotely resembling those of pronominal clitics. To the extent that certain ideas in the discussion above are on the right track, they are subject to further examining. It should therefore come as no surprise if they turn out to be insufficiently general or simply incorrect, and hence have to be revised or even abandoned when further related facts are brought to light. It is in this sense that linguistic theory is an empirical science; the form of theory is shaped by the form of the facts. This is the normal course of development of any rational inquiry, and in no way do the changes we need to make invalidate the general conceptual approach.

\section{References}

Aoun, J. (1979): On government, Case marking, and clitic placement. Ms. MIT

Aoun, J. (1981): The formal natural of anaphoric relations. Doctoral dissertation, MIT

Borer, H. (1984): Parametric syntax. Dordrecht: Foris

Butt, J.; Benjamin, C. (1988): Grammar of modern Spanish. London: Edward Arnold

Chomsky, N. (1981): Lectures on government and binding. Dordrecht: Foris

Chomsky, N. (1986): Barriers. Cambridge, MA: MIT Press

Chomsky, N. (1995): The Minimalist program. Cambridge, MA: MIT Press

Chomsky, N. (1999): Derivation by phase. Ms, MIT

Farkas, D. (1978): Direct and indirect object reduplication in Romanian. CLS 14. 88-97

Franco, J. (2000): Agreement as a continuum: The case of Spanish pronominal clitics. In: Beukema, F; den Dikken, M. (eds.): Clitic phenomena in European languages. Amsterdam: John Benjamin

Freeze, R. (1992): Existential and other locatives. Language 68,3. 553-595

Hurtado, A. (1984): Clitic chains. Ms., Simon Fraser University

Kayne, R. (1975): French syntax: The transformational cycle. Cambridge, MA: MIT Press 
Kayne, R. (1989): Facets of Romance participle agreement. In: Benicà, P. (ed.): Dialect variation and the theory of grammar. Dordrecht: Foris. 85-103

Kayne, R. (1993): Toward a modular theory of auxiliary selection. Studia Linguistica 47. 3-31

Kayne, R. (1994): Antisymmetry in syntax. Cambridge, MA: MIT Press

Lambrecht, K. (1999): Right dislocation. Ms, University of Texas, Austin

May, R. (1985): Logical form. Cambridge, MA: MIT Press

Mallison, G. (1986): Rumanian. London: Croom Helm.

Milner, J-C. (1978): De la syntaxe à l'interpretation. Paris: Le Seuil

Murrell, M.; Ştefănescu-Drăgăneşti, V. (1970): Rumanian. London: Teach Yourself Books

Nespor, M. (1984): The phonological word in Italian. In: van der Hulst, H.; Smith, N. (eds.): Advances in non-linear phonology. Dordrecht: Foris. 193-204

Nespor, M.; Vogel, I. (1982): Prosodic domains of external sandhi rules. In: van der Hulst, H.; Smith, N. (eds.): The structure of phonological representations, Part I. Dordrecht: Foris. 225-255

Peperkamp, S. (1996): On the prosodic representation of clitics. In: Kleinhenz, U. (ed.): Interfaces in phonology. Berlin: Akademie-Verlag. 102-127

Postal, P. (1969): On the so-called "pronouns" in English. In: Reibel, D. and Schane, S. (eds.): Modern studies in English. Englewood Cliffs, NJ: Prentice-Hall. 201-224

Rouveret, A.; Vergnaud, J.-R. (1980): Specifying reference to the subject. Linguistic Inquiry 11.77-202

Selkirk, E. (1980): On prosodic structure and its relation to syntactic structure. In: Fretheim, T. (ed.): Nordic prosody II. Trondheim:TAPIR. 11-40

Sportiche, D. (1996): Clitic constructions. In: Rooryck, J.; Zaring, L. (eds.): Phrase structure and the lexicon. Dordrecht: Kluwer Academic Publishers. 213-276

Steriade, D. (1980): Clitic doubling in the Romanian Wh-constructions and the analysis of topicalization. CLS 80. 282-297

Suñer, M. (1988): The role of agreement in clitic-doubled constructions. Natural Language and Linguistic Theory 6. 391-434

Uriagereka, J. (1995): Aspects of the syntax of clitics placement in western Romance. Linguistic Inquiry 26. $79-123$

Zwicky, A. (1977): On clitics. Bloomington: Indiana University Linguistics Club

Paul Law

Freie Universität Berlin

Gosslerstr. 2-4

14195 Berlin

Germany

law@zedat.fu-berlin.de 